\title{
SP-A2 contributes to miRNA-mediated sex differences in response to oxidative stress: pro-inflammatory, anti-apoptotic, and anti-oxidant pathways are involved
}

George T. Noutsios ${ }^{1 \dagger}$, Nithyananda Thorenoor ${ }^{1 \dagger}$, Xuesheng Zhang ${ }^{1}$, David S. Phelps ${ }^{1}$, Todd M. Umstead ${ }^{1}$, Faryal Durrani ${ }^{1}$ and Joanna Floros ${ }^{1,2^{*}}$

\begin{abstract}
Background: Human innate host defense molecules, surfactant protein A1 (SP-A1), and SP-A2 differentially affect the function and proteome of the alveolar macrophage (AM). We hypothesized that SP-A genes differentially regulate the AM miRNome.

Methods: Humanized transgenic mice expressing SP-A1 and SP-A2 were subjected to $\mathrm{O}_{3}$-induced oxidative stress $(\mathrm{OxS})$ or filtered air (FA), AMs were isolated, and miRNA levels were measured.

Results: In SP-A2 males, we found significant changes in miRNome in terms of sex and sex-OxS effects, with 11 miRNAs differentially expressed under OxS. Their mRNA targets included BCL2, CAT, FOXO1, IL6, NF-kB, SOD2, and STAT3. We followed the expression of these transcripts as well as key cytokines, and we found that (a) the STAT3 mRNA significantly increased at $4 \mathrm{~h}$ post OxS and returned to baseline at $18 \mathrm{~h}$ post OxS. (b) The anti-oxidant protein SOD2 level significantly increased, but the CAT level did not change after $4 \mathrm{~h}$ post OxS compared to control. (c) The anti-apoptotic BCL2 mRNA increased significantly (18 h post OxS), but the levels of the other transcripts were decreased. The presence of the SP-A2 gene had a protective role in apoptosis of AMs under OxS compared to mice lacking SP-A (knockout, KO). (d) Pro-inflammatory cytokine IL-6 protein levels were significantly increased in SP-A2 mice compared to KO (4 and $18 \mathrm{~h}$ post OxS), which signifies the role of SP-A2 in proinflammatory protein expression. (e) SOD2 and CAT mRNAs changed significantly in OxS indicating a plausible role of SP-A2 in the homeostasis of reactive oxygen species. (f) Gonadectomy of transgenic mice showed that sex hormones contribute to significant changes of the miRNome expression.
\end{abstract}

Conclusions: We conclude that SP-A2 influences the miRNA-mediated sex-specific differences in response to OxS. In males, these differences pertain to inflammatory, anti-apoptotic, and anti-oxidant pathways.

Keywords: Surfactant protein A, Ozone, Sex differences, STAT3, IL-6

\footnotetext{
* Correspondence: jfloros@pennstatehealth.psu.edu

${ }^{\dagger}$ Equal contributors

${ }^{1}$ Center for Host Defense, Inflammation, and Lung Disease (CHILD) Research,

Department of Pediatrics, The Pennsylvania State University College of Medicine, Hershey, PA 17033-0850, USA

${ }^{2}$ Department of Obstetrics and Gynecology, The Pennsylvania State

University College of Medicine, Hershey, PA 17033-0850, USA
} 


\section{Background}

The major function of the lung is to enable the uptake of oxygen from ambient air and eliminate carbon dioxide from the circulation. As the lung performs this lifesustaining function, it encounters many insults from the environment, such as ozone $\left(\mathrm{O}_{3}\right)$, particulate matter, allergens, bacteria, and viruses. Although healthy individuals bearing a well-regulated innate host defense system can neutralize these insults and maintain normal lung function, $\mathrm{O}_{3}$-induced oxidative stress $(\mathrm{OxS})$ can have dire effects on pulmonary innate host defense mechanisms and consequently on lung function [1].

In the alveolus, the alveolar macrophages (AMs), and to a lesser extent, the alveolar epithelial cells provide the primary innate defense against inhaled insults that may trigger a cascade of inflammatory responses after $\mathrm{O}_{3}$ exposure. The alveolus is lined by epithelial type I and type II cells and contains various epithelial cell metabolic products, including pulmonary surfactant as well as proteins from the lung interstitial fluid. Both surfactant proteins and lipid constituents of surfactant influence the regulation and function of AM [2-9].

Surfactant protein A (SP-A) is an important host defense molecule and has both innate host defense functions $[2,10-12]$ and surfactant-related functions that influence surfactant secretion and structure. We and others have highlighted the function of SP-A as innate immune molecule itself by showing that SP-A knockout (KO) mice are more prone to several infections compared to mice that express SP-A [13-17]. Previous studies have described the regulatory effects of SP-A either by directly affecting AM function [2, 18], the proteomic expression profile of AM $[9,19]$, and the cell shape and activation state of AM [20] or indirectly via the production of cytokines and chemokines by $\operatorname{AM}[11,21]$. Ozone exposure induces production of reactive oxygen species (ROS) by bronchoalveolar cells [22]. ROS damage the lung epithelium [23] and oxidize SP-A, and in turn, this compromises its innate immune functions [24-29]. The model used in this study provides advantage over other types of OxS, such as hyperoxia (which occurs over days), as it produces effects in several hours, allowing us to examine primary endpoints rather than secondary downstream events.

Ozone exposure has resulted in significant sex differences in survival, with females showing higher morbidity and mortality rates than males in several lung diseases including respiratory infections, COPD, asthma, and CF [30-34]. In our studies, we observed differences in survival rates between males and females after bacterial infection. Females appeared to resolve the bacterial respiratory infection more readily than males, but when OxS was introduced prior to infection, the outcome was reversed, i.e., females showed lower survival rates than males [13, 17, 35-38]. Moreover, these sex differences were further accentuated in SP-A KO mice or when SPA was oxidized, highlighting once again the important role of SP-A as a regulatory innate immune molecule $[13,17]$. The observed sex differences are in part, if not entirely, attributable to circulating gonadal hormones, which are believed to influence the innate immune responses [36], although the specific roles of these hormones and the underlying mechanisms of regulation remain unknown.

In the present study, we hypothesized that the two human SP-A1 and SP-A2 gene products differentially regulate the $\mathrm{AM}$ miRNome and this explains in part the previously observed differences in AM function and the AM proteome. We exposed male and female mice expressing SP-A1 or SP-A2 to $\mathrm{O}_{3}$ or FA (control), and we measured the expression levels of 372 micro-RNAs (miRNAs). The miRNAs with significantly altered levels in response to $\mathrm{OxS}$ were identified and used for further analysis. The findings showed that the AM miRNome is regulated by $\mathrm{O}_{3}$ exposure and that the SP-A2 male miRNome is associated with genes involved in inflammation pathways, regulation of reactive oxygen species, and apoptosis. Moreover, the miRNA differences in SPA2 male and female mice after gonadectomy showed that sex hormones play an important role in the observed miRNA differences by affecting the regulation of miRNAs. We postulate that miRNAs contribute to mechanisms involved in the regulation of $\mathrm{AM}$ function and the AM proteome by the SP-A2 gene in males.

\section{Methods}

\section{Animals}

We used humanized transgenic (hTG) C57BL/6 mice, expressing SP-A1 $\left(6 \mathrm{~A}^{2}\right)$ or SP-A2 $\left(1 \mathrm{~A}^{0}\right)$, or SP-A KO mice [39] at 12 weeks of age. Both males and synchronized females (regarding the estrous cycle) were used in this study. For synchronization, we used dirty bedding from a male's cage to stimulate estrus in females. Females were group-housed on male bedding for exactly 10 days before exposure to $\mathrm{FA}$ or $\mathrm{O}_{3}$. For each experimental condition, there were 3 animals/ group ( $n=36$ for miRNA study and $n=60$ for gene expression analysis, terminal deoxynucleotidyl transferase (TdT)-mediated dUTP Nick-End Labeling (TUNEL) assay, and miRNA analysis in gonadectomized mice). A total of 96 animals were used for the entire study. All procedures involving animals used protocols that were approved by the Institutional Animal Care and Use Committee at the Pennsylvania State University College of Medicine. All mice were maintained in facilities under pathogen-free conditions or in barrier containment facilities. 


\section{Ozone exposure}

Mice were exposed to $2 \mathrm{ppm}$ ozone $\left(\mathrm{O}_{3}\right)$ or to filtered air (FA) (control) at room temperature and 50\% humidity for $3 \mathrm{~h}$, as described previously [40]. In all cases, we used at least 3 mice/group, i.e., 3 males, 3 females, 3 SPA KO, 3 hTG SP-A2, 3 hTG SP-A1, 3 for $\mathrm{O}_{3}$ exposure and 3 for filtered air, and 3 male and 3 female SP-A2 and $\mathrm{KO}$ gonadectomized mice $(n=96)$. Each sample was analyzed individually, and we did not pool any samples. All FA and $\mathrm{O}_{3}$ exposures were conducted in parallel [41]. Mice were sacrificed 4 and $18 \mathrm{~h}$ after exposure.

\section{Mouse alveolar macrophage purification}

Mouse AMs were obtained by bronchoalveolar lavage (BAL) [9]. AMs were separated from the BAL by centrifugation $(150 \times g$ for $5 \mathrm{~min})$. The BAL supernatant, which was cell-free $(3.0 \mathrm{ml})$, was stored at $-80{ }^{\circ} \mathrm{C}$ until further use. The cell pellets were washed with $1 \times$ PBS (Gibco, Waltham, MA), and cells were counted. A fraction of the cells was placed in a cytocentrifuge and used to prepare cytospins, cells were stained, and a differential cell count was performed. AM purity was $95 \%$ as assessed by Papanikolaou staining. The remaining AM pellet was resuspended in $0.5 \mathrm{ml}$ solution of $90 \%$ fetal bovine serum (Gibco) and 10\% DMSO (Sigma-Aldrich, St. Louis, MO) and was cryopreserved in liquid nitrogen until further use.

\section{Isolation of miRNAs and qRT-PCR}

Total RNA from the AM was isolated using QIAzol Lysis Reagent (\#79306, Qiagen, Valencia, CA), and the miRNA-enriched fraction was isolated and purified with miRNeasy Micro Kit (\#217084, Qiagen). cDNA was generated with the miScript II RT Kit (\#218161, Qiagen) and then used as a template for real-time qPCR with the miScript SYBR Green PCR Kit (\#218075, Qiagen). The expression profiles of the 372 most abundantly expressed and best-characterized miRNAs in miRBase were determined by miRNA PCR Array (Array \#MIMM-3001Z, Qiagen). The miRNA PCR array covers most of the mouse miRNA orthologs $(\sim 90 \%)$ of the human miRNA annotations. The variability across the 3 samples is assessed by $p$ values $(p<0.05)$. The miRNAs with significantly changed levels were studied further $(p<0.05)$.

\section{Data analysis}

miRNAs (mmu-miR-21a-5p, mmu-miR-23a-3p, mmumiR-2137, and mmu-let-7c-5p) were constant under our experimental conditions and therefore were selected for use in the normalization of all miRNA values. The arithmetic mean values of these miRNAs were used for normalization, and all statistical analyses were done after normalization.
The Ct cutoff was 35 . The fold change $\left(2^{-\Delta \Delta C t}\right)$ was calculated as the normalized individual miRNA expression $\left(2^{-\Delta \mathrm{Ct}}\right)$ in each individual experimental specimen divided by the same normalized miRNA expression 2 $-\Delta \mathrm{Ct}$ in the corresponding $\mathrm{KO}$ (control). The fold regulation represented fold change results in a biologically meaningful way. Fold change values greater $>1$ indicated a positive or an upregulation, and the fold regulation was equal to the fold change. Fold change values $<1$ indicated a negative or downregulation, and the fold regulation was the negative inverse of the fold change. The $p$ values were calculated based on Student's $t$ test of the replicate $2^{-\Delta \mathrm{Ct}}$ values for each miRNA in the $\mathrm{KO}$ control group and treatment groups. All data can be found in Additional file 1. Data analysis was performed with manufacturer's software (https://www.qiagen.com/ us/resources/geneglobe/).

\section{Gonadectomy and ozone exposure}

Male and female SP-A2 mice were gonadectomized (Gx) as described [36]. Two weeks after gonad removal, mice were exposed to $\mathrm{O}_{3}(2 \mathrm{ppm})$ for $3 \mathrm{~h}$ and were sacrificed $4 \mathrm{~h}$ post $\mathrm{OxS}$. The RNA from AM was isolated, and the differential expression of miRNAs was quantified as tag count data [42] by RNA sequencing at the Pennsylvania State University College of Medicine Genomic Core Facility, with default false discovery rate 0.1 (cutoff). The miRNAs identified from Gx mice were selected based on the average tag count data $(\geq 100)$ and with good correlation data count between mice (2 out of 3 ). We successfully identified 63 miRNAs in Gx-SP-A2 and KO (male and female) and used these in the present analysis. First, the changes in miRNA expression in SP-A2 mice were calculated by normalizing to $\mathrm{KO}$, i.e., the level of expression of each individual experimental miRNA (i.e., in GxSP-A2) was divided by the same miRNA expression in the corresponding Gx-KO. Next, the differentially expressed miRNAs between SP-A2 males and females were determined by dividing a specific individual male miRNA by the corresponding specific female miRNA. Lastly, the fold changes of the identified miRNAs from Gx (SP-A2 male vs female) were compared to the corresponding miRNAs identified from non-gonadectomized (NGx) SP-A2 male vs female. Samples from 12 animals (6 males and 6 females for SP-A2 and KO) were individually analyzed.

\section{Gene expression assays}

AMs were lysed by the addition of QIAzol Lysis Reagent (Qiagen). Total RNA was purified with Direct-zol RNA Mini Prep kit (\#R2052, Zymo Research, Irvine, CA), and RNA concentration and quality were confirmed by Nanodrop and Bioanalyzer. RNA was reversetranscribed using RT2 first strand kit (\#330401, Qiagen), 
according to the manufacturer's protocol. Real-time PCR was performed using RT2 SYBR Green ROX qPCR Mastermix (\#330520, Qiagen) on a QuantStudio 12K Flex Real-Time PCR System (Applied Biosystems, Waltham, MA) at the Pennsylvania State University College of Medicine Genomic Core Facility. The expression levels of GAPDH, SOD2, CAT, IL-6, STAT3, BCL2, FOXO1, FOXO3, BECN1, IKK $\beta$, and NF-kB-p65 were detected by qRT-PCR with specific RT2 qPCR Primer Assays (Qiagen). Samples from 3 animals/treatment (FA and $\mathrm{O}_{3}$ ) and 3 replicates/animal were individually analyzed and quantified relative to GAPDH mRNA expression. The relative expression levels of target genes were determined by the equation $2^{-\Delta C T}$, and $2^{-\Delta \Delta C T}$, in which $\Delta C_{T}$ was calculated as follows: $\Delta C_{T}=C_{T}$ gene-of-interest $-C_{T}$ housekeeping gene. The $\Delta \Delta C_{T}$ was calculated by the difference between $\Delta C_{T}$ values of experimental $\left(\mathrm{O}_{3}\right.$ exposure) and control (FA exposure) $\left(\Delta \Delta C_{T}=\Delta C_{T \text { experimental }}-\Delta C_{T \text { control }}\right)$.

\section{Western blot analysis and antibodies}

Equal amounts of AM protein lysates for each set of samples from control and $\mathrm{O}_{3}$ exposure mice were separated by sodium dodecyl sulfate-polyacrylamide gel electrophoresis (SDS-PAGE), transferred to PVDF membrane, and the expression levels of STAT3, NF-kB-p65, FOXO1, CAT, SOD2, and GAPDH were detected by Western blotting with specific antibodies. Samples from 3 animals/ treatment (control and $\mathrm{O}_{3}$ ) were individually analyzed and quantified relative to GAPDH expression. The antibodies utilized were obtained from the following sources: NF-kB (\#8242), FOXO1 (\#2880), GAPDH (\#2118), STAT3 (\#12640), SOD2 (\#13194), and catalase (\#14097) (Cell Signaling Technology, Danvers, MA).

\section{Measurement of IL- 6 , TNF- $\alpha$, and IL-1 $\beta$}

Data from BAL from 3 animals/treatment $\left(\mathrm{FA}, \mathrm{O}_{3}\right)$ and 3 replicates/animal were used to assess levels of IL-6, TNF$\alpha$, and IL-1 $\beta$ using a conventional enzyme-like immunosorbent assay (ELISA) as per vendor's protocol (\#SEM03015A, SEM03113A, and SEM03109A, SABiosciences, Valencia, CA). Levels of IL-6, TNF- $\alpha$, and IL- $1 \beta$ were measured using BAL samples. (a) BAL from SP-A2 mice after $4 \mathrm{~h}$ of ozone $\left(\mathrm{O}_{3}\right)$ exposure was used to measure IL-6 levels by diluting the BAL 1:2, 1:4, 1:8, and 1:16. (b) BAL from SP-A2 and $\mathrm{KO}$ mice after $18 \mathrm{~h}$ of $\mathrm{O}_{3}$ exposure was used to measure IL- 6 levels by diluting $1: 2$, whereas the levels of TNF- $\alpha$ and IL- $1 \beta$ were measured without BAL dilution. The optical density of the end product was measured at $450 \mathrm{~nm}$ using Tecan Spectrafluor spectrophotometer (Agilent Technologies, Santa Clara, CA).

\section{TUNEL assay}

The TdT-mediated dUTP Nick-End Labeling (TUNEL; \#4822-96-K, HT Titer TACS Assay, Trevigen,
Gaithersburg, MD) assay was used to detect the ability of ozone to induce apoptosis according to the vendor's protocol. Briefly, AM cells (70,000 cells/well) after $18 \mathrm{~h}$ of $\mathrm{O}_{3}$ exposure from hTG SP-A2 and $\mathrm{KO}$ mice were fixed in $3.7 \%$ formaldehyde in $1 \times$ PBS. The cells were incubated for $1 \mathrm{~h}$ at $37{ }^{\circ} \mathrm{C}$ in the presence of $\mathrm{TdT}$. In positive control TACS-Nuclease was used, whereas no TdT was added in the unlabeled control (data not shown). The apoptotic cell absorbance was measured at $450 \mathrm{~nm}$ using Tecan Spectrafluor spectrophotometer (Agilent Technologies).

\section{Statistical analysis}

All experiments were done using 3 animals for each condition. Replicates were analyzed using Student's $t$ test; a $p$ value of $<0.05$ was considered statistically significant. Bonferroni correction of the $p$ values was applied to account for the sex, treatment, and gene variability in our miRNA arrays. Therefore, we considered significant miRNA changes with $p<0.0166$. Moreover, to control false discovery rates (FDR) within our miRNA arrays, we also determined the FDR by Benjamini and Hochberg approach [43]. We focused our analysis only on miRNAs passing both the Bonferroni correction and an FDR-adjusted threshold of 0.05 (expressed as $q<0.05$ ) (see Additional file 1).

To report sex differences, a two-way analysis of variance (ANOVA) with factors of treatment and sex was performed to show a significant interaction between sex and treatment, meaning that the treatment effect differed in the two sexes (see Additional file 1). Also, the effect of gonadal removal in $\mathrm{O}_{3}$ response was assessed by one-way ANOVA (see Additional file 3).

\section{Results}

\section{SP-A genes differentially regulate the AM miRNome}

The expression levels of the hTG SP-A1 and SP-A2 AM miRNomes were determined in males and females that were exposed to FA or $\mathrm{O}_{3}$ and compared to the corresponding KO AM. The miRNome levels are presented as volcano plots to show the fold change regulation differences between levels of miRNAs in hTG and KO mice, as well as their statistical significance (Figs. 1 and 2).

Under basal conditions, which in our experimental model is exposure to FA, panel A in Fig. 1 shows a very tightly packed cluster of data points with relatively few data points exceeding the cutoff for significance (Bonferroni corrected $p<0.0166$ ), indicating that there are a few differences between FA-exposed SP-A1 males and $\mathrm{KO}$ males. In panel $\mathrm{B}$, when the same comparison is made with female mice, we observe a multitude of miRNAs that are significantly upregulated. It is immediately obvious by comparing the shaded areas in panels $\mathrm{A}$ and $\mathrm{B}$ that there are many more differences 


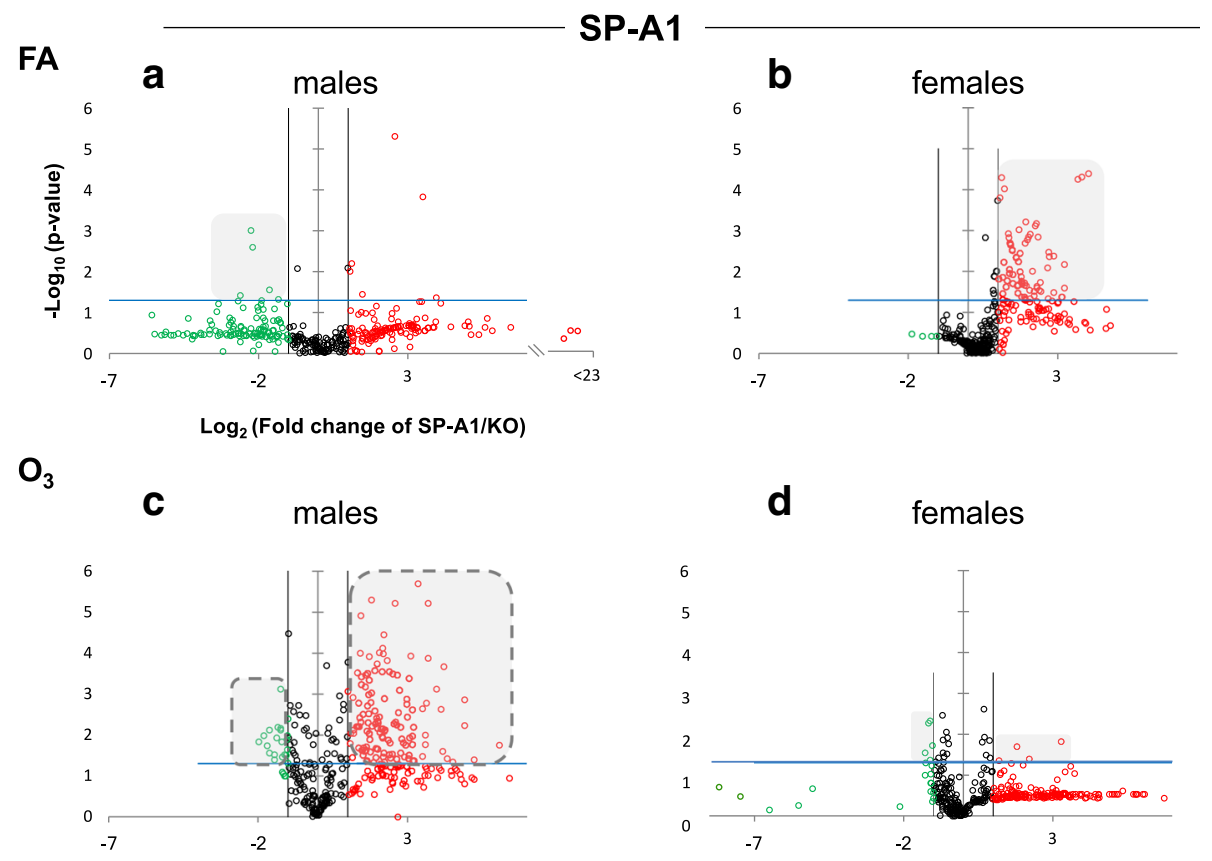

Fig. 1 Volcano plots indicating the statistical significance of SP-A1 AM miRNome expression levels compared to SP-A KO under FA or $\mathrm{O}_{3}$ exposure for males and females. The $x$-axis plots the $\log _{2}$ of the fold changes, while the $y$-axis plots the $-\log _{10}$ of their $p$ values based on $t$ test of the replicate raw $C t$ data (see the "Methods" section). Each plot has 3 vertical lines. The middle vertical line that is graded corresponds to 0 changes. The lines on either side represent $\geq 2$-fold differences. Dots in the volcano plots above the blue horizontal line identify fold changes with statistical significance of at least the Bonferroni corrected $p<0.0166$. The red and green dots represent miRNAs that were upregulated $\geq 2$-fold and downregulated $\leq-2$-fold, respectively, compared to KO. Black dots signify miRNAs that were regulated less than 2 -fold times (i.e., $-2 \leq x \leq 2 ; x$ is the fold change). a Male SP-A1 mice compared to KO exposed to FA. $\mathbf{b}$ Female SP-A1 mice compared to KO exposed to FA. c Male SP-A1 mice compared to KO after $\mathrm{O}_{3}$ exposure. $\mathbf{d}$ Female SP-A1 mice compared to $\mathrm{KO}$ after $\mathrm{O}_{3}$ exposure. The shaded gray areas show the differences in the miRNAs that are highly and significantly regulated between the two sexes and the two conditions compared to $\mathrm{KO}$. The shaded gray areas with a broken outline are to highlight the significantly changed miRNAs in SP-A1 male $\mathrm{O}_{3}$ exposed mice and SP-A2 male $\mathrm{O}_{3}$ exposed mice (Fig. 2). The $x$-axis on $\mathbf{a}$ is broken to allow comparison between all panels

(of both magnitude and significance) in females compared to males. Following $\mathrm{O}_{3}$ exposure (panels $\mathrm{C}$ and $\mathrm{D})$, the SP-A1 mice show a very different picture. The female mice (panel D) exhibit fewer differences of lower magnitude than what is observed with the males (panel C). The pattern seen in OxS is almost the opposite of the basal conditions (compare shaded areas in Fig. 1).

When we compare the SP-A2 hTG males and females under basal conditions, we do not see any robust differences as with the SP-A1 hTG (Fig. 2, panels $\mathrm{a}$ and $\mathrm{b}$, respectively). However, under OxS, females have less pronounced differences than males (Fig. 2, panels $\mathrm{c}$ and d). Under OxS, the male miRNome in both SP-A1 and SP-A2 mice is more responsive compared to females and exhibits a higher number of changing miRNAs that reach the Bonferroni corrected significance threshold $p<0.0166$ (compare shaded areas). A two-way ANOVA test for the sex and treatment effects showed that the $F$ stat for the SP-A2 mice regarding the sex effect is $F=26.34$ with $F$ crit $=3.84$ and $p=3.23 \times 10^{-7}$. The $F$ stat for the interaction between the two factors (sex and treatment) was $F=25.25$ with $F$ crit $=3.84$ and $p=5.65 \times 10^{-7}$.
The same analysis for the SP-A1 mice miRNome did not show that sex, treatment, or the combination of these two factors were significantly different (see Additional file 1). The ANOVA test for the SP-A1 mice to check the effect of treatment (FA or $\mathrm{O}_{3}$ ), sex (male, female), and the interaction between the two variables (treatment and sex effects) showed that the $F$ stat for SP-A1 mice was $F=1.17$ lower than the $F$ crit $=3.85$ and $p$ value not significant $p=0.279$. These data show that in the AM miRNome, there is a difference between sexes in response to $\mathrm{O}_{3}$ exposure with the presence of SP-A1 or SP-A2.

\section{Regulation of AM miRNome in response to OxS}

Next, we focused on the AM miRNAs whose expression is altered in response to OxS from SP-A1 and SP-A2 male and female mice. We compared the SP-A1 and SPA2 AM miRNome altered $\geq 2$-fold between males and females under basal conditions and OxS (Fig. 3). We found that in SP-A1 mice, in males, 92 miRNAs were changed under control conditions and 49 under $\mathrm{O}_{3}$, whereas in females, only 25 miRNAs were changed in FA and 24 in OxS. The same comparison in SP-A2 AM miRNome showed that for males, 137 miRNAs were 

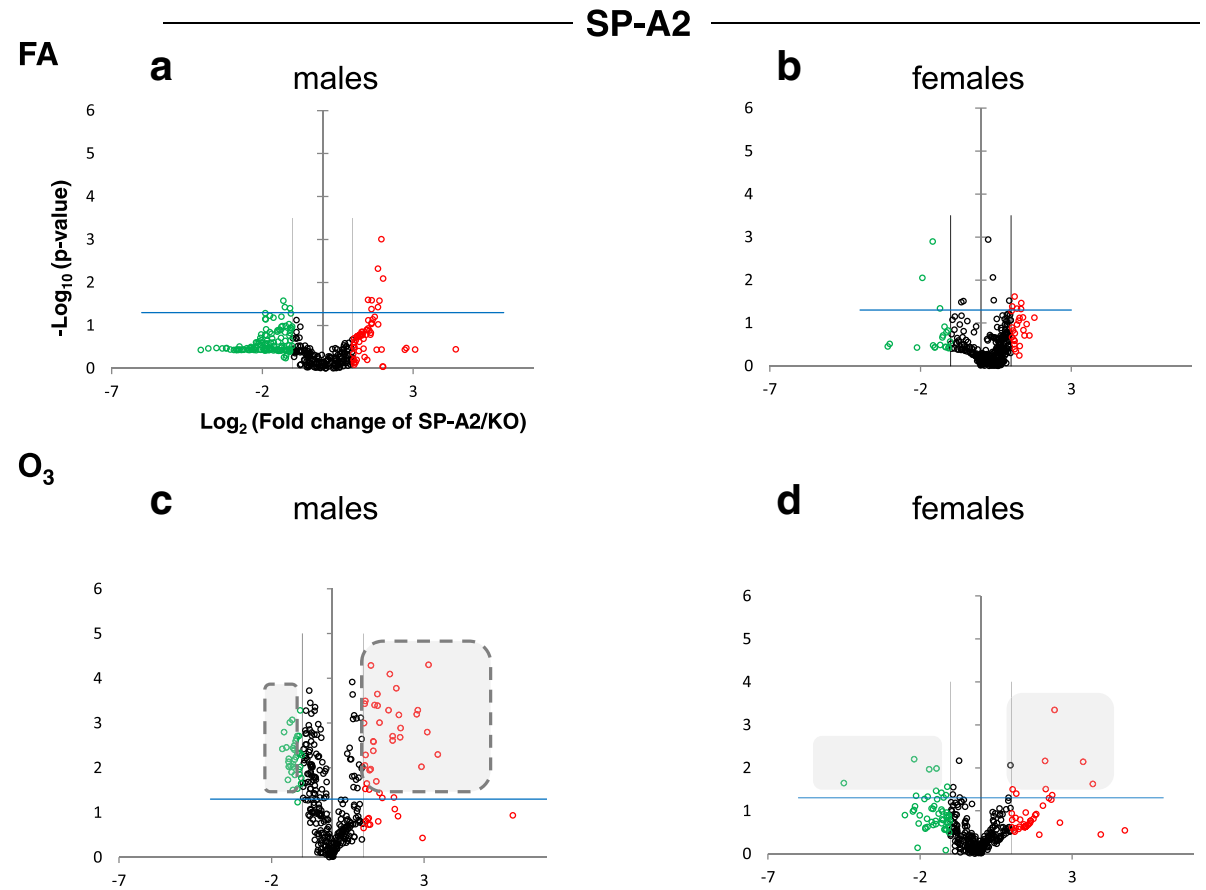

Fig. 2 Volcano plots (as described in Fig. 1) indicating the statistical significance of SP-A2 AM miRNome expression levels compared to SP-A KO under $\mathrm{FA}$ or $\mathrm{O}_{3}$ exposure for males and females. a Male SP-A2 mice compared to KO exposed to FA. $\mathbf{b}$ Female SP-A2 mice compared to KO after FA exposure. c Male SP-A2 mice compared to $\mathrm{KO}$ after $\mathrm{O}_{3}$ exposure. $\mathbf{d}$ Female SP-A2 mice compared to $\mathrm{KO}$ after $\mathrm{O}_{3}$ exposure. The shaded gray areas with a broken outline compare the significantly changed miRNAs in SP-A2 male $\mathrm{O}_{3}$ exposed mice and SP-A1 male $\mathrm{O}_{3}$ exposed mice (Fig. 1)

regulated in FA and 48 miRNAs in $\mathrm{O}_{3}$, while in females, only 20 were regulated in FA and 100 by OxS (Fig. 3).

\section{Sex- and gene-specific AM miRNAs that are regulated by OxS}

To identify sex- and gene-specific AM miRNome changes in response to $\mathrm{OxS}$, we compared via Venn diagrams the SP-A1- and SP-A2-regulated miRNAs that were altered in the two conditions (FA and $\mathrm{O}_{3}$ ) (Fig. 3 and Additional file 2). The diagrams show the distribution of the differentially expressed SP-A1 and SP-A2 miRNAs regulated $\geq 2$-fold that are unique or common under basal conditions and under $\mathrm{OxS}$ in SP-A1 or SPA2 male and female mice.

We next assessed the miRNAs unique and common for male and female SP-A1 and SP-A2 mice after $\mathrm{O}_{3}$ and FA exposure. Out of the total 372 miRNAs of our array, we identified 49 miRNAs that are unique to SP-A1 male and 24 miRNAs unique to SP-A1 females in $\mathrm{OxS}$, and 153 miRNAs were found to be in common in SP-A1 males and females after $\mathrm{O}_{3}$ exposures (Fig. 3). In the case of SP-A2 mice, we identified 48 miRNAs unique to SP-A2 male and 100 miRNAs unique to SP-A2 females in $\mathrm{OxS}$, and only $18 \mathrm{miRNAs}$ were commonly identified after $\mathrm{O}_{3}$ exposure. Similarly, under control conditions in filtered air (FA), more miRNAs $(n=122)$ were in common in SP-A1 male and female mice than in SP-A2 $(n=24)$ (Fig. 3). These data indicate sex variability in the SP-A2 and SP-A1 miRNome.

Ingenuity Pathway Analysis of the AM miRNome and the genes that they affect in response to OxS in SP-A2 male mice To better understand and integrate the AM miRNome data, we performed Ingenuity Pathway Analysis (IPA) for the AM miRNAs whose expression was significantly altered by OxS. Only miRNAs that were shown to pass the corrected Bonferroni $p<0.0166$ and an FDRadjusted $q<0.05$ were used to ensure that sex, treatment, gene, and array variability do not lead to false discoveries. IPA for the male SP-A2 miRNome $(n=31$ miRNAs were male-specific) showed several mRNA transcripts, the expression of which could be affected by miRNAs that were changed by OxS. We found direct associations between some of these miRNAs with IL-6, NF-kB, STAT3, BCL2, and FOXO1 mRNAs.

miR-191-5p, which binds IL-6 [44], is downregulated. The levels of microRNAs (miR-21-5p, miR-181a-5p, miR-1195) in response to $\mathrm{O}_{3}$ are shown in Table 1; these are known to interact directly with STAT3.

We found five miRNAs to be directly associated with the BCL2 gene. Both miR-21-5p and miR-16-5p were significantly downregulated in our study. miR-195a-5p that has the same seeding sequence with miR-16-5p and is predicted to bind BCL2 mRNA was also 

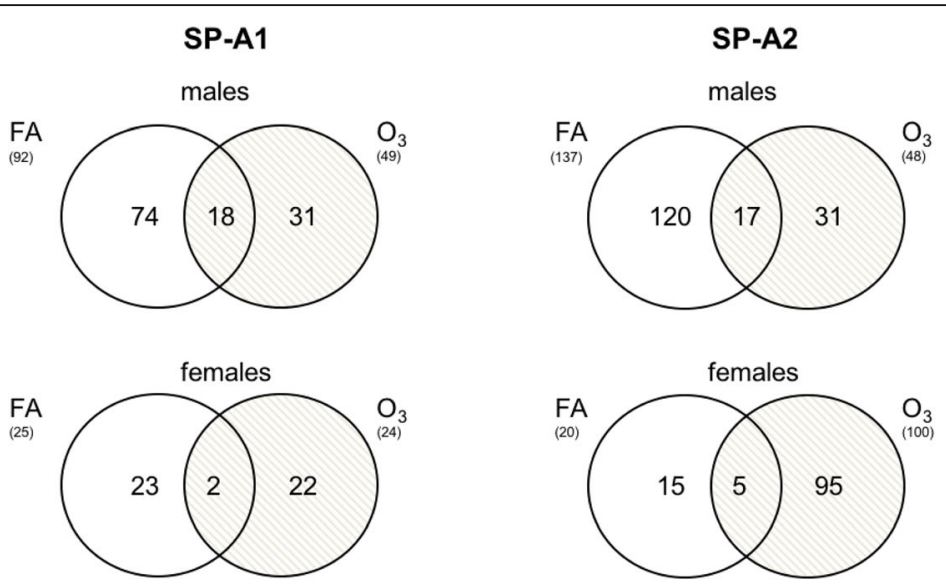

$\mathrm{O}_{3}$

\section{FA}
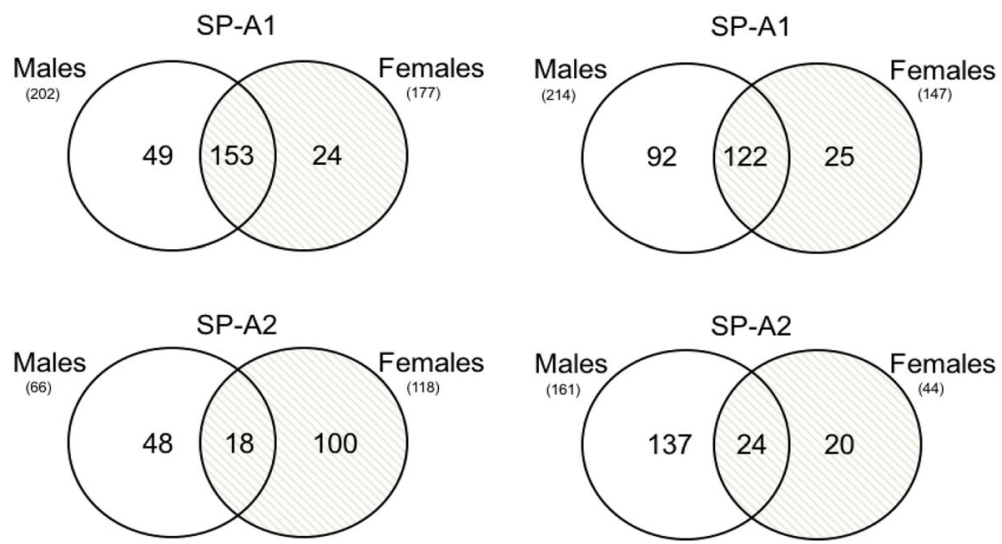

Fig. 3 Venn diagrams showing the distribution of differentially expressed SP-A1 and SP-A2 AM miRNAs that changed $\geq 2$-fold compared to SP-A $\mathrm{KO}$ AM, which are unique or common (overlapping areas) in $\mathrm{FA}$ and $\mathrm{O}_{3}$ exposure. Also, the figure shows the effect of sex on the expression of miRNAs after $\mathrm{FA}$ and $\mathrm{O}_{3}$ exposure. Venn diagrams are showing unique and commonly identified miRNAs among SP-A1 and SP-A2 male and female hTG mice. Out of the total 226 miRNAs identified in male and female SP-A1, 49 identified miRNAs are unique to male and 24 are unique to female; 153 miRNAs are identified in common after $\mathrm{O}_{3}$ exposure. In the case of SP-A2, out of the 166 miRNAs identified, 48 miRNAs are unique to male and 100 are unique to female; 18 miRNAs were identified in common after $\mathrm{O}_{3}$ exposure. However, under control conditions, more miRNAs $(n=122)$ were in common in the SP-A1 male and female mice than in the SP-A2 $(n=24)$

downregulated while miR-153-3p that was also found to bind BCL2 experimentally (by Western blot, qRT-PCR, and LUC) [45] was increased.

Two miRNAs (miR-9-5p and miR-183-5p) were regulated by $\mathrm{O}_{3}$, and these were shown to target the NF-kB protein and mRNA experimentally (Western blot and qRT-PCR) [46] and by in silico analysis (TargetScan). miR9-5p expression levels were downregulated. miR-183-5p, which was upregulated, probably has the opposite effect. FOXO1 is targeted by a multitude of miRNAs that are changed in our study miR-9-5p, miR-21-5p, miR-16-5p, miR-183-5p [47], miR-486b-5p, and miR-153-3p. The above six miRNAs were either up- or downregulated in our experiments (Table 1 ) and could potentially regulate the expression levels of FOXO1 in AM by OxS.
Only the male SP-A2 AM miRNome in response to $\mathrm{O}_{3}$ associates with genes involved in OxS

When an IPA like the one done with data of male SP-A2 hTG mice was performed, using the 95 miRNAs found in the SP-A2 female AM miRNome, the main associations found were for cervical cancer and reproductive system disorders (data not shown). Although the SP-A2 females express the same miRNAs as the males, the changes resulting from $\mathrm{O}_{3}$ exposure are lower than those observed in the males, leading to the identification of different pathways. For the SP-A1-regulated miRNAs in males that changed in response to $\mathrm{O}_{3}$ (31 miRNAs), no major networks were identified, whereas for the SPA1-regulated miRNAs in females (22 miRNAs), we found that tumor protein p53 may be involved in the 
Table 1 Levels and statistical significance of the male SP-A2 AM miRNAs compared to SP-A KO in OxS and shown by IPA to be directly associated with genes IL-6, NF-kB, STAT3, BCL2, and FOXO1

\begin{tabular}{lll}
\hline Mature ID & Fold regulation & $p$ value \\
\hline miR-191-5p & -2.1515 & 0.00196 \\
miR-153-3p & 4.2526 & 0.000167 \\
miR-15b-5p & -1.7279 & 0.01395 \\
miR-16-5p & -1.8298 & 0.000532 \\
miR-181a-5p & -1.5004 & 0.000539 \\
miR-183-5p & 2.0782 & 0.000372 \\
miR-195a-5p & -1.2763 & 0.030639 \\
miR-21a-5p & -2.4629 & 0.009501 \\
miR-9-5p & -3.0084 & 0.001602 \\
miR-486b-5p & 1.407 & 0.196574 \\
miR-1195 & 2.1028 & 0.000323 \\
\hline - indicates downregulation & &
\end{tabular}

- indicates downregulation

regulation of 4 miRNAs identified in our study, along with argonaute-2 protein (AGO2), which is involved in biogenesis of miRNAs (data not shown).

\section{Effect of gonadectomy and OxS on expression of miRNAs} in SP-A2 male and female mice

To identify the effect of sex hormones on the expression of miRNAs after OxS, we performed miRNA expression analysis in AM from gonadectomized (Gx) SP-A2 and $\mathrm{KO}$ male and female mice and compared it with that of non-gonadectomized (NGx) mice after $\mathrm{O}_{3}$ exposure. For this analysis, we used 63 miRNAs that were identified in both NGx (male and female) and Gx (male and female) groups. Of these, in the NGx (male vs female) group, only 37 miRNAs had their levels significantly changed (fold change $\geq 2$ ) (Fig. 4, Additional file 3). In the Gx group (male vs female) compared to the corresponding NGx (male vs female) group, expression of 2 miRNAs (5.4\%) was significantly increased (fold change $\geq 2$ ), and expression of 34 miRNAs $(94.6 \%)$ was significantly decreased (fold change $\leq 2$ ). Of the 37 miRNAs differentially expressed in Gx male and female, 17 miRNAs (45.9\%) are Gx female specific and 7 miRNAs (18.9\%) are Gx male specific (Fig. 4 inset, Additional file 3). Moreover, a one-way ANOVA pertaining to the gonadectomy effect on the miRNA expression showed a significant difference with $F$ stat $=11.98$ with $F$ crit $=3.92$ and $p=0.00073$ (see Additional file 3). These data indicate that sex hormones play an important role in the observed miRNA sex differences by affecting regulation of miRNAs, as most of the miRNAs that were increased in NGx were decreased in Gx.

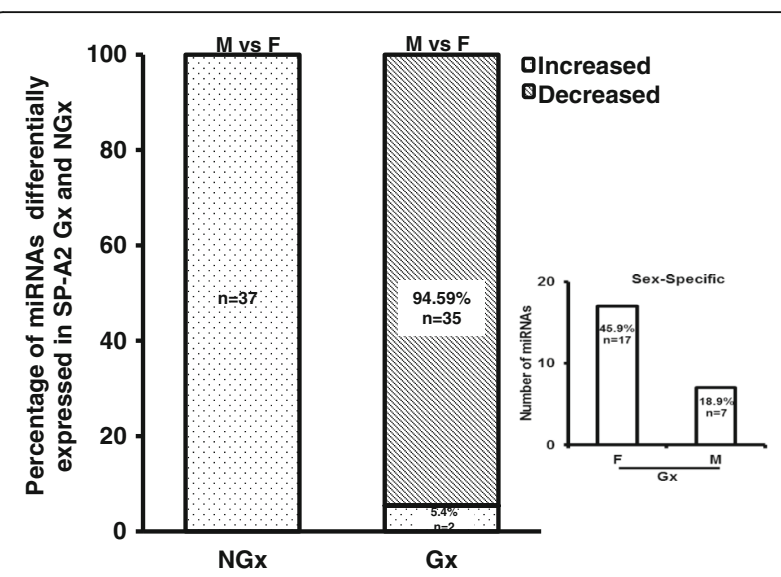

Fig. 4 The effect of gonadectomy and OxS on AM miRNA expression profiles of SP-A2 mice. The differentially expressed miRNAs in SP-A2 non-gonadectomized (NGX) and gonadectomized (GX) mice were identified after normalizing to corresponding NGx and Gx KO. NGx shows the miRNAs $(n=37)$ that changed significantly $(\geq 2$-fold) in OxS when males were compared to females. Gx depicts the comparison of Gx values (male vs female) to NGx (male vs female). Out of the same 37 miRNAs (found to have their levels increased in NGx), 2 miRNAs (5.4\%) showed a significant increase ( $\geq 2$-fold) and 35 miRNAs (94.59\%) showed a significant decrease ( $\leq 2$-fold). Inset depicts the comparison, of the 37 differentially expressed miRNAs, between Gx male and female. Out of 37 miRNAs studied, 17 miRNAs (45.9\%) are significantly increased in female ( $\geq 2$-fold), and 7 miRNAs (18.9\%) are significantly increased in male ( $\geq 2$-fold)

\section{Expression of genes regulated by OxS in SP-A2 males}

We performed qRT-PCR to assess the expression levels of SOD2, CAT, IL-6, STAT3, BCL2, FOXO1, FOXO3, BECN1, IKK $\beta$, and NF-kB-p65 genes at mRNA level in the male SP-A2 AM. We found that under OxS, the levels of STAT3 mRNA were increased significantly $(p<0.05)$ by 5 -fold (Fig. $5 \mathrm{a})$. No significant differences were observed for the other mRNAs studied.

We examined the protein expression levels of STAT3, NF-kB, FOXO1, CAT, and SOD2 in the male SP-A2 AM after $4 \mathrm{~h}$ OxS. The Western blot analysis indicated no significant difference in the protein levels of STAT3, NF$\mathrm{kB}$, FOXO1, and CAT at $4 \mathrm{~h}$ after OxS exposure, whereas for SOD2, a significant increase was observed compared to control (Fig. 5a, inset).

To account for half-life differences and study further the expression of these genes, we used AM from male SP-A2 and $\mathrm{KO}$ mice after $18 \mathrm{~h}$ of exposure to $\mathrm{O}_{3}$ and found a significant increase in the mRNA level of BCL2 (Fig. 5b). The levels of the other genes studied (SOD2, CAT, IL-6, FOXO3, BECN1, and IKK $\beta$ ) were decreased significantly (Fig. 5b). In contrast, in $\mathrm{KO}$, the expression of SOD2 and CAT was increased significantly, but no significant changes in the expression of the other genes were observed (IL-6, STAT3, BCL2, FOXO3, BECN1, IKK $\beta$, and 


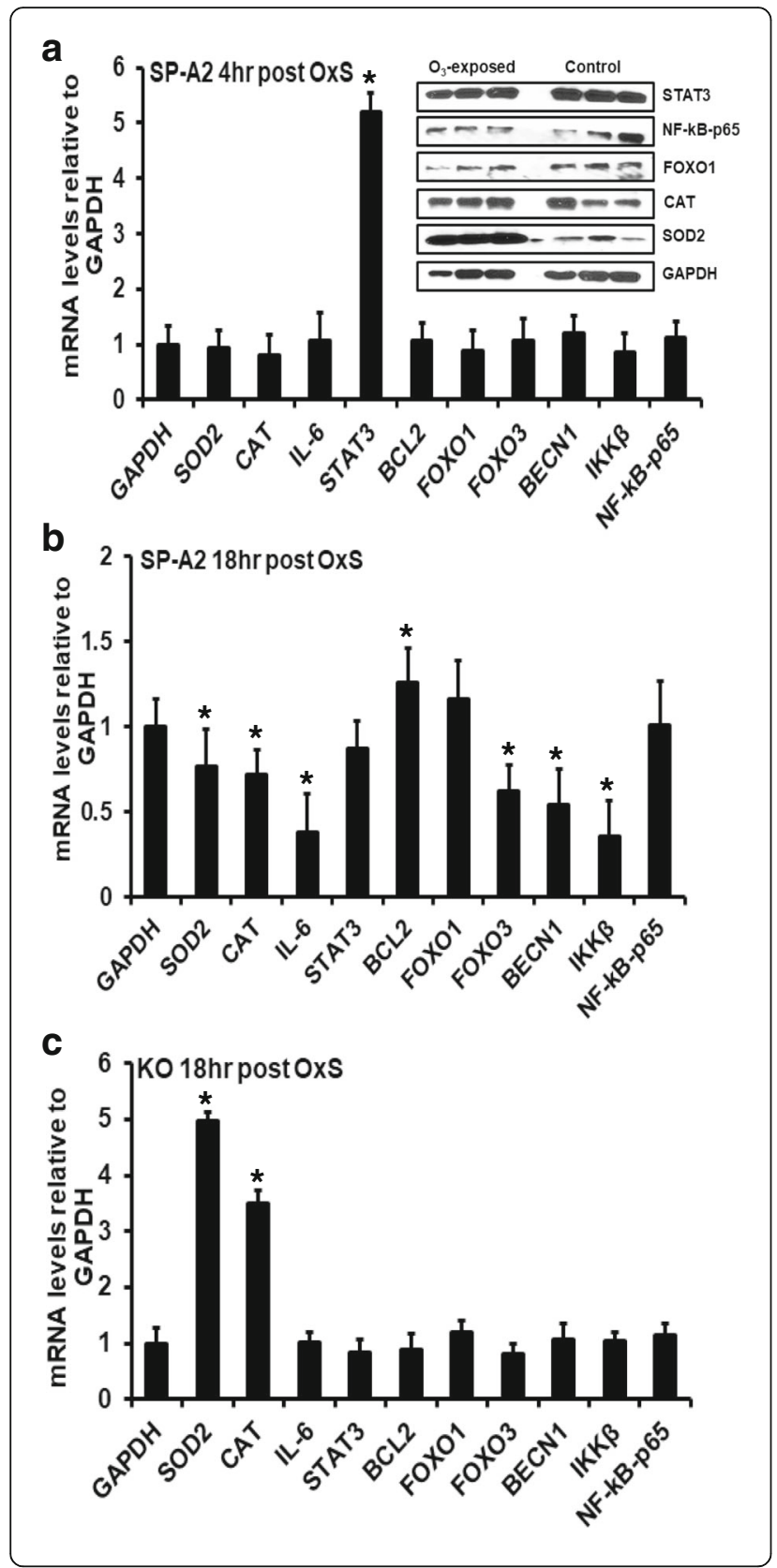

Fig. 5 Effect of $\mathrm{O}_{3}$ in males. a mRNA levels of GAPDH, SOD2, CAT, IL-6, STAT3, BCL2, FOXO1, FOXO3, BECN1, IKKß, and NF-kB-p65 genes were measured in AM of male SP-A2 mice $4 \mathrm{~h}$ after $\mathrm{O}_{3}$ exposure. mRNA levels were measured by qRT-PCR and normalized to GAPDH. STAT3 mRNA levels were significantly increased by 5 -fold $(p<0.05)$, while the levels of other mRNAs did not change significantly compared to FA exposure. Inset depicts protein expression levels of STAT3, NF-kB-p65, FOXO1,

CAT, and SOD2 in AM of male SP-A2 mice $4 \mathrm{~h}$ after $\mathrm{O}_{3}$ exposure. Protein levels were measured by Western blot analysis and normalized to

GAPDH. $\mathbf{b}$ mRNA levels of the above mentioned genes were measured by qRT-PCR $18 \mathrm{~h}$ post exposure. In male SP-A2, $\mathrm{O}_{3}$ exposure significantly increased BCL2 mRNA levels compared to FA $(p<0.05)$. The mRNA levels of SOD2, CAT, IL-6, FOXO3, BECN1, and IKKB were significantly decreased compared to FA $(p<0.05)$. $\mathbf{c}$ In KO, mRNA levels of SOD2 and CAT were significantly increased $(p<0.05) 18 \mathrm{~h}$ post exposure, while the levels of other mRNAs did not change significantly compared to FA. Data were generated using 3 animals/group, $n=18$, and 3 replicate/animal

NF-kB-p65 (Fig. 5c). A trend of increase in the level of FOXO1 was observed in SP-A2 and KO (Fig. 5b, c).

To investigate the role of IL-6 in the increased STAT3 levels, we measured IL-6 protein by ELISA in the BAL of male SP-A2 hTG mice after exposure to $\mathrm{O}_{3}$ and FA. We found that IL-6 levels were increased significantly compared to control conditions (FA) at $4 \mathrm{~h}$ post OxS (Fig. 6a) and at $18 \mathrm{~h}$ post OxS (Fig. 6b). We also measured the levels of IL-1 $\beta$ and TNF- $\alpha$ at $18 \mathrm{~h}$ post OxS in SP-A2 and KO. We observed a significant increase in their levels in SP-A2 compared to FA (Fig. 6b), whereas in the case of $\mathrm{KO}$, the level of these proteins was significantly decreased after $\mathrm{O}_{3}$ exposure compared to FA (Fig. 6b), indicating a role of SP-A2 in these processes.

\section{Apoptosis induced by OxS in male SP-A2 and KO mice}

We used a TUNEL assay to assess apoptosis. We analyzed apoptotic cells from AM of SP-A2 and KO male mice at $18 \mathrm{~h}$ post $\mathrm{OxS}$. In response to $\mathrm{O}_{3}$ exposure, no significant differences were observed between SP-A2 and $\mathrm{KO}$. However, a small but significant decrease in apoptotic cells was observed in SP-A2 $\mathrm{O}_{3}$-exposed mice compared to SP-A2 FA-exposed mice, whereas an increase in apoptotic cells was observed in $\mathrm{O}_{3}$-exposed KO mice compared to FA-exposed KO (Fig. 7). Our results indicate that ozone differentially affects apoptosis in $\mathrm{KO}$ and SP-A2 AM, with SP-A2 providing perhaps some protection from the effect of OxS.

\section{Discussion}

SP-A is an important host defense molecule. In humans, there are two SP-A functional genes, SFTPA1 (SP-A1) and SFTPA2 (SP-A2), and their gene products have been shown to differ functionally from each other [39, 48-50]. Differences have been seen in the proteomic expression of $\mathrm{AM}$ and the $\mathrm{AM}$ actin cytoskeleton after exposure to SP-A1 or SP-A2 variants [20, 48]. We 


\section{a $4 \mathrm{~h}$ post $\mathrm{O}_{3}$}

b $18 \mathrm{~h}$ post $\mathrm{O}_{3}$
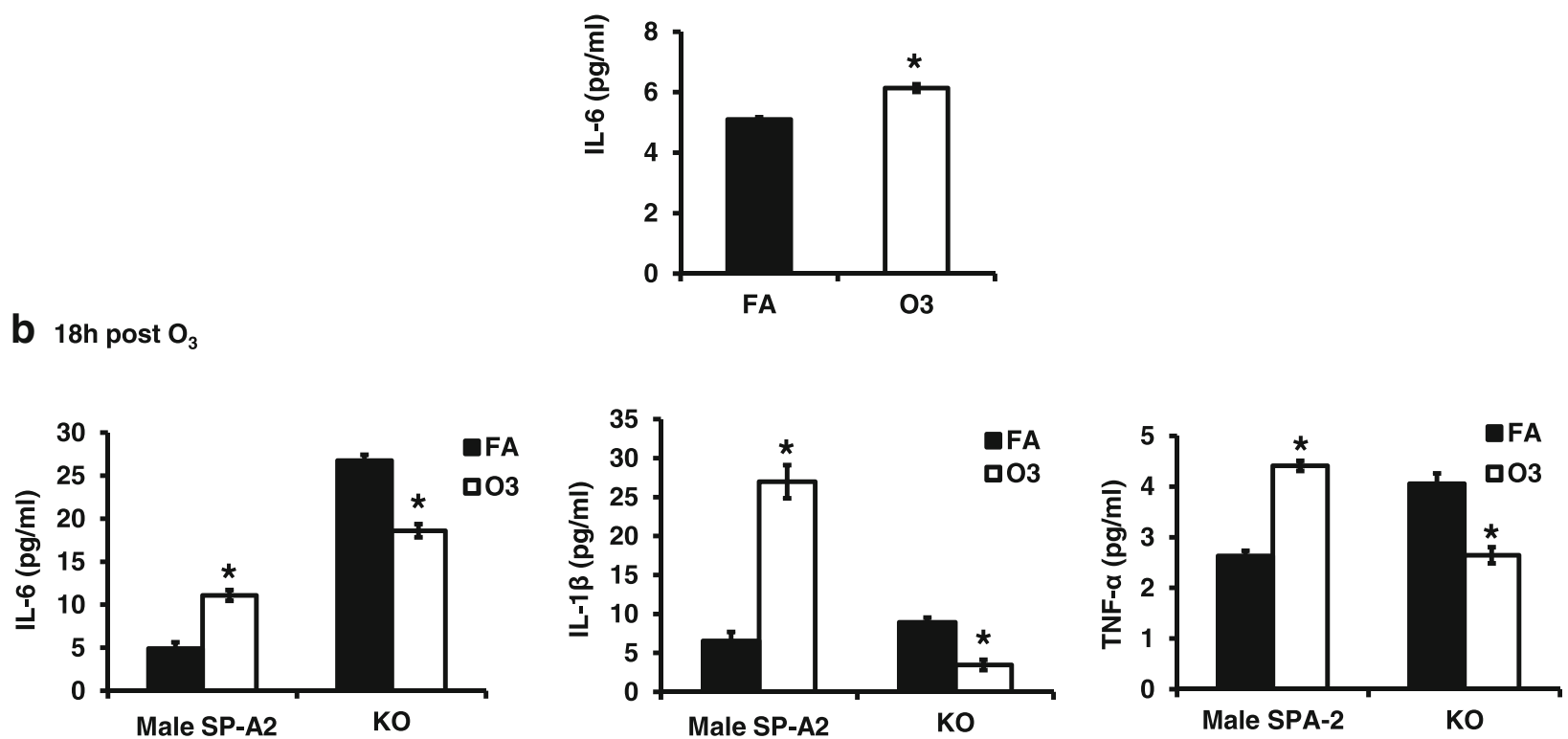

Fig. 6 Effect of $\mathrm{O}_{3}$ on IL-6, TNF-a, and IL-1 $\beta$ protein levels in the bronchoalveolar lavage of male SP-A2 and KO mice compared to FA exposure. a Protein levels were measured by ELISA 4 h post exposure. OxS significantly increased IL-6 levels in SP-A2 male mice compared to FA (control) SP-A2 mice $(p<0.05)$. b Protein levels were measured at $18 \mathrm{~h}$ post exposure in SP-A2 and KO. OxS significantly increased IL-6, IL-1 $\beta$, and TNF-a in SP-A2 mice $(p<0.05)$ and significantly decreased in $\mathrm{KO}$ mice $(p<0.05)$. Data were generated using 3 animals/group, $n=18$ and 3 replicate/animal

have also previously shown sex differences in the $\mathrm{KO}$ AM proteome after treatment with SP-A1 or SP-A2 gene products where more changes occurred with SP$\mathrm{A} 1$ and SP-A2 treatment in females and males, respectively [51]. The present study was done to further

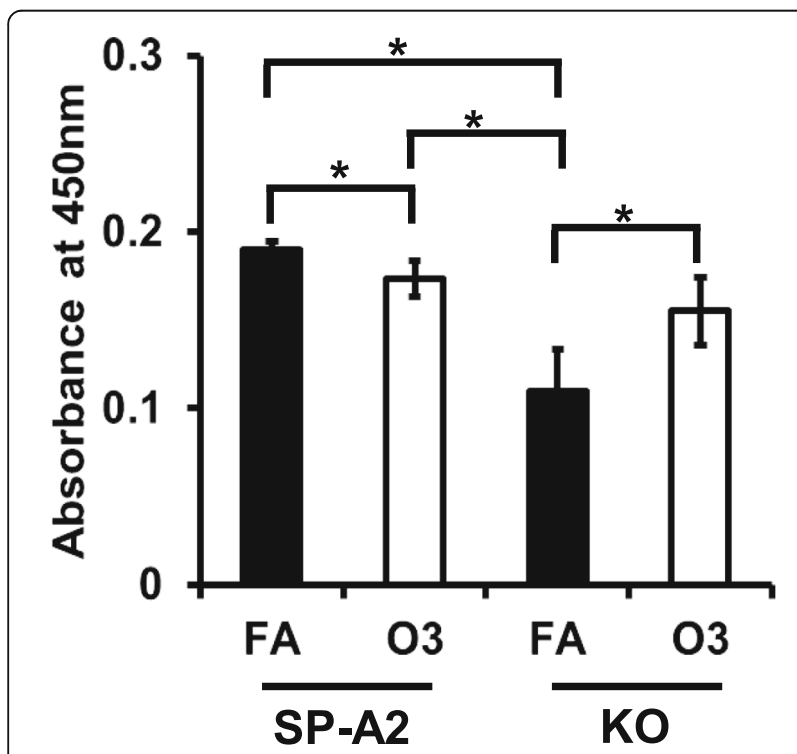

Fig. 7 Effect of $\mathrm{O}_{3}$ on AM apoptosis by TUNEL assay. The TUNEL assay was performed at $18 \mathrm{~h}$ post exposure to ozone in SP-A2 and $\mathrm{KO}$ mice by using AM cells $(70,000$ cells/well). Data were generated using 3 animals/group $(n=12)$ and 4 replicate/animal $(p<0.05)$ understand mechanisms underlying the previously observed sex differences in the AM function and proteome in response to SP-A genes (SP-A1 and SP-A2).

We studied the AM miRNome in male and female mice that express human SP-A1 and SP-A2 after $\mathrm{O}_{3}$ exposure and compared it to that of $\mathrm{KO}$ mice that do not express SP-A. In both male and female miRNomes, changes were found after exposure to $\mathrm{O}_{3}$ that may reflect an attempt to mitigate the consequences of OxS. In the male miRNome of both transgenic mice (SP-A1 and SP-A2), there was an increase in the number of miRNAs that changed significantly after $\mathrm{O}_{3}$ exposure, whereas in females, OxS did not change the miRNome substantially.

We found miR-191-5p, shown previously to regulate IL6 [44], to be downregulated and this could increase the levels of IL-6, which is consistent with our experimental findings. IL- 6 was found to be expressed in the BAL of males after $\mathrm{O}_{3}$ exposure, but not in females [38]. IL-6 has been shown to have both pro- and anti-inflammatory functions [52], and in mice, IL-6 overexpression has been shown to protect against hyperoxia-induced lung mitochondrial damage [53].

Pro-inflammatory cytokine IL-6 has been reported to activate STAT3 via phosphorylation [54-59] and OxS to trigger STAT3 phosphorylation that is responsible for transcriptional activation of cytokine-encoding genes that are involved in inflammation and cell injury [60]. miR-21- 
5p, miR-181a-5p, and miR-1195 shown in the present study to be altered significantly in response to $\mathrm{O}_{3}$ have also been shown to directly interact with STAT3. Specifically, miR-21-5p is predicted to bind STAT3 mRNA (TargetScan). In our experimental conditions, the observed downregulation of this miRNA is associated with increased levels of STAT3. However, activation of STAT3 by IL-6 has been shown experimentally to increase expression of miR-21-5p [61]. miR-1195 has been shown by in silico analysis to bind STAT3 [62], while miR-181a-5p has been shown with quantitative RT-PCR to be increased after activation of STAT3 by IL-6 [63]. In response to OxS, the expression levels of miR-21-5p, miR-1195, miR181a-5p, and miR-191-5p (as shown in Fig. 8) were changed significantly and this could result in the observed increased levels of STAT3. We postulate that an activated or dimerized STAT3 translocates to the nucleus where transcription initiation of pro-inflammatory genes takes place (Fig. 8). Moreover, the significantly increased STAT3 mRNA levels and the increased levels of TNF- $\alpha$, IL- 6 , and
IL-1 $\beta$ after $\mathrm{O}_{3}$ exposure in the SP-A2 male AM (4 and $18 \mathrm{~h}$ post $\mathrm{OxS}$ ) support this possibility. The IL-6 driven STAT3 phosphorylation and activation in $\mathrm{OxS}$ has been shown before [64] and has been linked with inflammation, cell injury, and cancer $[65,66]$, but the potential role of SP-A2 in this process is novel.

STAT3 activates other genes involved in cell cycle and upregulates anti-apoptotic genes such as BCL2 [67]. Of interest, BCL2 was found to be regulated by the male SP-A2 AM miRNome in OxS; BCL2 has been shown previously to be expressed in AM [68]. We found five SP-A2-regulated miRNAs that are directly associated with the BCL2 gene. miR-21-5p is predicted to bind both, BCL2 and STAT3 mRNAs (TargetScan), and miR-16-5p has been shown to bind BCL2 by several experimental approaches (Western blot, qRT-PCR, and luciferase reporter assays) $[69,70]$. Both miR-21-5p and miR-16-5p were downregulated significantly in our study, and this is associated with increased mRNA levels of BCL2 (at $18 \mathrm{~h}$ post exposure, Fig. 5b) that may

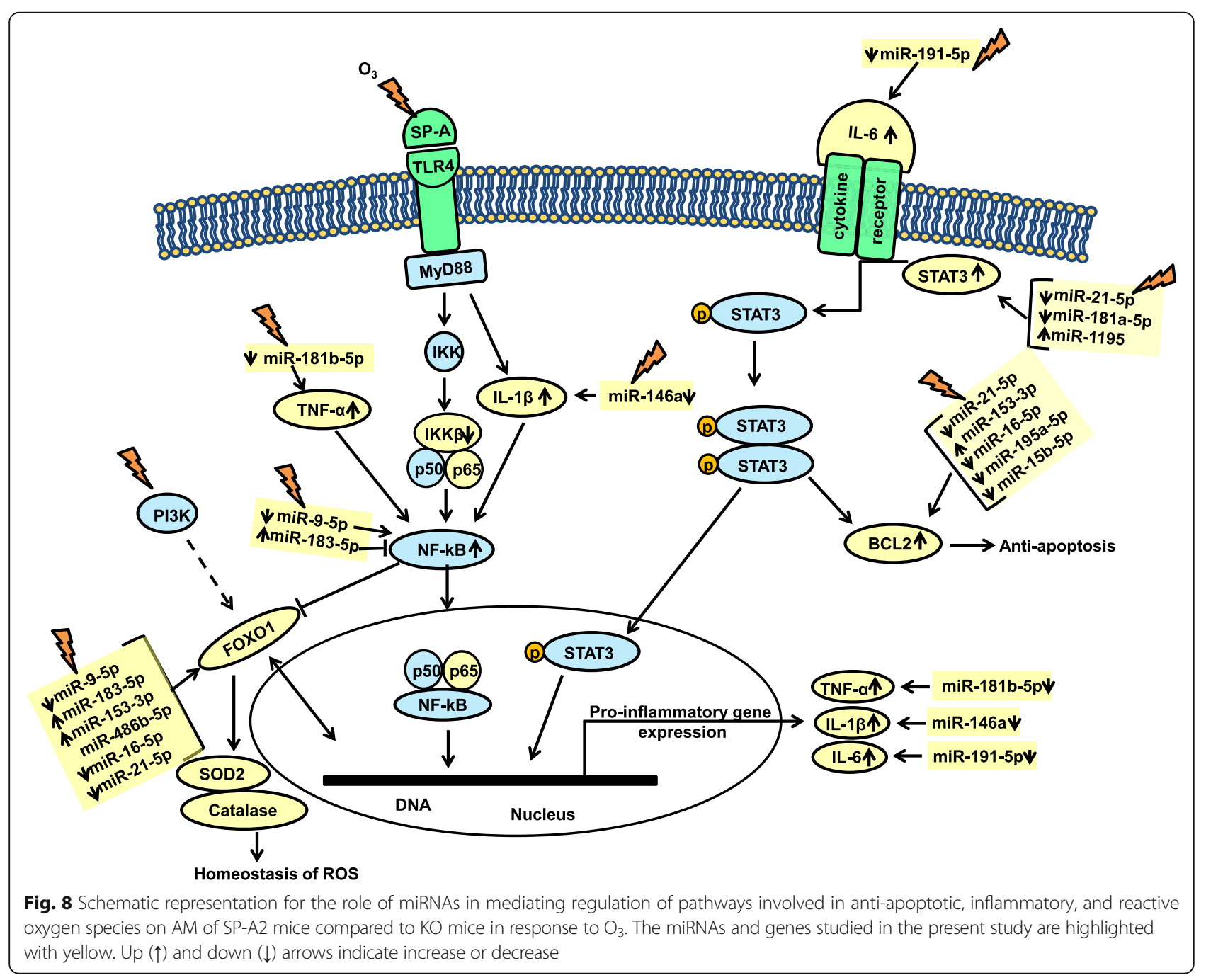


contribute to inhibition of apoptosis and cell proliferation in SP-A2 males, but not in $\mathrm{KO}$ males, where the expression of BCL2 did not change (Fig. 5c). miR-195a$5 p$ that has the same seeding sequence with miR-16-5p, is predicted to bind BCL2 mRNA, and this was also downregulated in our study and may increase further the anti-apoptotic effects of miR-21-5p and miR-16-5p. miR-153-3p that binds BCL2 experimentally (by WB, qRT-PCR and LUC) [45] was increased in our study and may have the opposite effect, i.e., attenuating the anti-apoptotic effect of the other miRNAs. A further support for a role of BCL2 in the inhibition of apoptosis and cell proliferation in response to $\mathrm{O}_{3}$ is provided by the TUNEL assay. Fewer apoptotic cells were found in SP-A2 compared to FA and an increase in apoptotic cells in $\mathrm{KO}$ compared to FA (Fig. 7). Of interest, in the absence of SP-A (i.e., in KO mice), higher inflammation and lower survival rates were observed in both FA- and ozone-exposed mice compared to wild type animals [35, 40]. These findings together indicate that ozone differentially affects apoptotic pathways in SP-A2 and $\mathrm{KO}$ mice and that the lungs from SP-A2 mice may have a protective anti-apoptotic role.

Another transcriptional factor that we found to be targeted by the male SP-A2 AM miRNome and is involved in immune responses is NF-kB [71]. Two miRNAs (miR-9-5p and miR-183-5p) were significantly changed by $\mathrm{O}_{3}$, and these were shown to target the NF-kB mRNA experimentally [46] and by in silico analysis (TargetScan), respectively. miR-9-5p expression levels were downregulated significantly compared to control, and this may increase NF-kB mRNA levels that in turn may induce anti-proliferative effects [72]. miR-183-5p that was upregulated may have the opposite effect on NF-kB. Our data showed a decrease in IKK $\beta$ without any change in the NF-kB-p65 levels. It is well established that the IKK $\beta$-dependent NF-kB signaling is a regulator of cell survival, immunity, and inflammation [73]. We know that SP-A activates NF-kB in THP-1 cells, a human macrophage-like cell line [74]. The signal may be induced through MyD88, IL-1 $\beta$, and IKK $\beta$ kinase (IKK), with subsequent NF-kB translocation to the nucleus to facilitate transcription of pro-inflammatory genes, such as TNF- $\alpha$ and IL-1 $\beta$ as observed in the present study. We have observed that $\mathrm{O}_{3}$ exposure decreases the ability of SP-A to activate the NF-kB pathway as indicated by lack of increase of nuclear p65 and decrease of cytoplasmic IKBa [25]. However, no studies up to now have addressed the impact of $\mathrm{O}_{3}$ on SP-A2-mediated NF-kB activation.

The two transcriptional factors identified here, NF-kB and STAT3, are believed not to act in isolation but to cross talk with each other in inflammatory conditions [75]. It has been documented in the literature that IL-6 increases levels of NF-kB [76] and siRNA inhibition of IL-6 results in reduced levels of NF-kB [77]. Along with
IL-6, TNF- $\alpha$ also increases the binding of NF-kB to STAT3 [78]. In our experimental conditions, $18 \mathrm{~h}$ post OxS, we observed an increase in TNF- $\alpha$ and IL-1 $\beta$ levels and $4 \mathrm{~h}$ post $\mathrm{OxS}$ we observed a decrease in miR-181-5p and miR-146a; these miRNAs are known to target TNF$\alpha$ and IL- $1 \beta$, respectively [79]. This may result in an increased level of TNF- $\alpha$ and IL- $1 \beta$ (Figs. $6 \mathrm{~b}$ and 8 ). Moreover, an increased level of TNF- $\alpha$ and IL-1 $\beta$ may activate NF- $k B$, causing its translocation to the nucleus to facilitate transcription of pro-inflammatory genes as discussed above. Furthermore, an activated NF-kB has been shown to increase activation of BCL2 [80], whereas a mutant NF-kB decreased BCL2 [81]. The present data indicate that SP-A2 may play a role in these processes in the male AM miRNome in response to OxS.

Another transcript in our study that was targeted by several miRNAs is the FOXO1. This mRNA is targeted by miR-9-5p [47], miR-21-5p, miR-16-5p (TargetScan), miR-183-5p [47], miR-486b-5p [82], and miR-153-3p [47]. From the above six miRNAs, all but miR-486b-5p were changed significantly in our study and these potentially could regulate the expression levels of FOXO1 in AM under OxS (Fig. 8). FOXOs are transcription factors known to be involved in the homeostasis of ROS and can function as a negative feedback loop to control cellular reactive oxygen species [83]. FOXO1 regulates the expression of anti-oxidant genes such as CAT and SOD2, both of which are known to neutralize free radicals generated by ROS. Although no significant changes were observed in FOXO1 mRNA levels at 4 or $18 \mathrm{~h}$ post $\mathrm{OxS}$ in either SP-A2 or KO mice, the mRNA levels of SOD2 (superoxide dismutase) and CAT (catalase) significantly decreased at $18 \mathrm{~h}$ post $\mathrm{OxS}$ in SP-A2 males. However, for SOD2 (but not for CAT) at $4 \mathrm{~h}$ post OxS, the protein levels were increased. In contrast, in $\mathrm{KO}$ males, the mRNA levels of SOD2 and CAT were significantly increased. This striking difference between the $\mathrm{KO}$ and the hTG indicates that the SP-A2 gene may play a role in the homeostasis of ROS.

Apart from the miRNAs that affect the expression of FOXO1, activated NF-kB through TNF- $\alpha$ and IL- $1 \beta$ may repress the expression of FOXO1. This in turn causes inhibition of FOXO1-mediated anti-oxidant defense mechanism at post-transcriptional level during OxS in AM. Our previous studies have shown that SP-A may prime AM to be ready to respond to oxidative stress. Moreover, because SP-A is shown to be oxidized more readily than other proteins after ozone exposure [40], we had postulated that SP-A may serve as an anti-oxidant "sacrificial lamb" by scavenging ROS and thus protect other molecules from immediate oxidative damage [40]. In the absence of SP-A, there may be an increased level of oxidative stress and this may compromise the function of AM [35]. Furthermore, the AM expression 
profile of SP-A2 mice was most similar to that of WT mice, particularly for proteins regulated by $\mathrm{Nrf2}$, which were downregulated compared to $\mathrm{KO}$, suggesting that these proteins were utilized to ameliorate the effect of oxidative stress in SP-A2 [9, 48], by OxS.

\section{Conclusions}

In summary, SP-A2 regulates miRNAs that play a role in pathways involved in inflammation, apoptosis, and ROS homeostasis. The observations made pertain only to the male SP-A2 AM miRNome in response to OxS exposure and not to females. The involvement of sex hormones in the observed miRNA sex-specific differences was supported by the findings in gonadectomized mice where we observed that the regulation of the miRNome of the SP-A2 male mice compared to that of female mice in response to $\mathrm{OxS}$ is significantly altered after gonadectomy. Collectively, our findings support and in part explain our previous observations of sex differences after OxS, where we observed females to be more susceptible in terms of survival to $\mathrm{OxS}$ than males. Here, we show that the male SP-A2 AM miRNome in response to OxS is associated with OxSrelated inflammatory genes, regulation of ROS, and apoptosis. In females, although these miRNAs are expressed, their levels do not change significantly. The miRNAs identified here may correlate with the male survival advantage in OxS compared to females.

\section{Additional files}

Additional file 1: Original miRNA data used to generate Figs. 1 and 2. (XLSX $1320 \mathrm{~kb}$ )

Additional file 2: Original miRNA data used to generate Venn Diagrams (Fig. 3). (XLSX 75 kb)

Additional file 3: Original gonadectomy miRNA tag count data (Fig. 4). (XLSX $123 \mathrm{~kb}$ )

\begin{abstract}
Abbreviations
AM: Alveolar macrophage; ANOVA: Analysis of variance; BCL2: B cell lymphoma 2; BECN1: Beclin-1; CAT: Catalase; $F$ crit: Critical value in F distribution; $F$ stat: $F$ test or Fisher's statistic; FA: Filter air; FDR: Benjamini and Hochberg false discovery rate; FOXO1: Forkhead box 01; FOXO3: Forkhead box O3: Gx: Gonadectomized; hTG: Humanized transgenic mice; IKKß: Inhibitor of nuclear factor kappa-B kinase subunit beta; IL-1ß; Interleukin 1 beta; IL6: Interleukin 6; KO: Knockout; miRNA: Micro-RNA; NF-kB: Nuclear factor kappalight-chain-enhancer of activated B cells; NGx: Non-gonadectomized; $\mathrm{O}_{3}$ : Ozone; OxS: Oxidative stress; qRT-PCR: Quantitative real-time polymerase chain reaction; SFTP-A1: Gene encoding SP-A1; SFTP-A2: Gene encoding SP-A2; SOD2: Superoxide dismutase 2; SP-A: Surfactant protein A; STAT3: Signal transducer and activator of transcription 3; TNF-a: Tumor necrosis factor alpha; TUNEL: TdT-mediated dUTP Nick-End Labeling
\end{abstract}

\section{Acknowledgements}

We would like to thank Dr. Rongling Wu for his consultation on the statistical analysis of miRNAs with multiple comparisons and Dr. Yuka Imamura from Pennsylvania State University College of Medicine Genomic Core Facility for the identification of miRNAs from Gx samples.

\section{Funding}

This work was supported by NIHR01HL34788 and CHILD fund, Department of Pediatrics, College of Medicine, at Pennsylvania State University.

\section{Authors' contributions}

GTN designed the study, performed the experiments, run the statistics, analyzed and synthesized the data, and contributed to the manuscript writing. NT performed the experiments, analyzed and synthesized the data, and contributed to the manuscript writing. XZ and TMU performed the maintenance and breeding of mouse lines, exposed the mice to experimental conditions ( $\mathrm{FA}$ and $\mathrm{O}_{3}$ ), and isolated the alveolar macrophages. FD performed all the gonadectomy experiments. DSP contributed to the data analysis and synthesis and manuscript writing. JF provided oversight to the entire project and involved in the data analysis, integration, and writing of the manuscript. All authors read and approved the final manuscript.

\section{Ethics approval}

All protocols used in this study were evaluated and approved by the Pennsylvania State University College of Medicine Institutional Animal Care and Use Committee and conformed to the guidelines of the National Institutes of Health on the care and use of laboratory animals.

\section{Consent for publication}

Not applicable

\section{Competing interests}

The authors declare that they have no competing interests.

\section{Publisher's Note}

Springer Nature remains neutral with regard to jurisdictional claims in published maps and institutional affiliations.

Received: 22 June 2017 Accepted: 1 November 2017 Published online: 04 December 2017

\section{References}

1. Al-Hegelan M, Tighe RM, Castillo C, Hollingsworth JW. Ambient ozone and pulmonary innate immunity. Immunol Res. 2011;49:173-91.

2. Phelps DS. Surfactant regulation of host defense function in the lung: a question of balance. Pediatr Pathol Mol Med. 2001;20:269-92.

3. Huang W, Wang G, Phelps DS, Al-Mondhiry H, Floros J. Combined SP-Ableomycin effect on cytokines by THP-1 cells: impact of surfactant lipids on this effect. Am J Physiol Lung Cell Mol Physiol. 2002;283:L94-L102.

4. van Iwaarden JF, Claassen E, Jeurissen SH, Haagsman HP, Kraal G. Alveolar macrophages, surfactant lipids, and surfactant protein $B$ regulate the induction of immune responses via the airways. Am J Respir Cell Mol Biol. 2001;24:452-8

5. Kremlev SG, Phelps DS. Effect of SP-A and surfactant lipids on expression of cell surface markers in the THP-1 monocytic cell line. Am J Phys. 1997;272: L1070-7.

6. Kremlev SG, Umstead TM, Phelps DS. Surfactant protein A regulates cytokine production in the monocytic cell line THP-1. Am J Phys. 1997;272:L996-1004

7. Song M, Phelps DS. Comparison of SP-A and LPS effects on the THP-1 monocytic cell line. Am J Physiol Lung Cell Mol Physiol. 2000;279:L110-7.

8. Phelps DS, Umstead TM, Floros J. Sex differences in the response of the alveolar macrophage proteome to treatment with exogenous surfactant protein-A. Proteome Sci. 2012;10:44

9. Phelps DS, Umstead TM, Quintero OA, Yengo CM, Floros J. In vivo rescue of alveolar macrophages from SP-A knockout mice with exogenous SP-A nearly restores a wild type intracellular proteome; actin involvement. Proteome Sci. 2011;9:67.

10. Wright JR. Immunoregulatory functions of surfactant proteins. Nat Rev Immunol. 2005:5:58-68.

11. Crouch E, Wright JR. Surfactant proteins a and $d$ and pulmonary host defense. Annu Rev Physiol. 2001;63:521-54.

12. Griese M. Pulmonary surfactant in health and human lung diseases: state of the art. Eur Respir J. 1999;13:1455-76.

13. Mikerov AN, Haque R, Gan X, Guo X, Phelps DS, Floros J. Ablation of SP-A has a negative impact on the susceptibility of mice to Klebsiella pneumoniae infection after ozone exposure: sex differences. Respir Res. 2008;9:77. 
14. LeVine AM, Bruno MD, Huelsman KM, Ross GF, Whitsett JA, Korfhagen TR. Surfactant protein A-deficient mice are susceptible to group B streptococcal infection. J Immunol. 1997;158:4336-40.

15. LeVine AM, Whitsett JA, Gwozdz JA, Richardson TR, Fisher JH, Burhans MS, Korfhagen TR. Distinct effects of surfactant protein A or D deficiency during bacterial infection on the lung. J Immunol. 2000;165:3934-40.

16. LeVine AM, Gwozdz J, Stark J, Bruno M, Whitsett J, Korfhagen T. Surfactant protein-A enhances respiratory syncytial virus clearance in vivo. J Clin Invest. 1999;103:1015-21.

17. Mikerov AN, Hu S, Durrani F, Gan X, Wang G, Umstead TM, Phelps DS, Floros J. Impact of sex and ozone exposure on the course of pneumonia in wild type and SP-A (-/-) mice. Microb Pathog. 2012;52:239-49.

18. Floros J, Wang G, Mikerov AN. Genetic complexity of the human innate host defense molecules, surfactant protein A1 (SP-A1) and SP-A2-impact on function. Crit Rev Eukaryot Gene Expr. 2009:19:125-37.

19. Phelps DS, Umstead TM, Floros J. Sex differences in the response of the alveolar macrophage proteome to treatment with exogenous surfactant protein-A. Proteome Sci. 2011;10:44.

20. Tsotakos N, Phelps DS, Yengo CM, Chinchilli VM, Floros J. Single-cell analysis reveals differential regulation of the alveolar macrophage actin cytoskeleton by surfactant proteins $A 1$ and A2: implications of sex and aging. Biol Sex Differ. 2016;7:18

21. Floros J, Phelps D. Pulmonary surfactant protein A; structure, expression, and its role in innate host defense. In: Nakos G, Lekka M, editors. Surfactantupdate of intensive care medicine. Greece: University of loannina; 2002. p. 87-102. [Nakos G, ME L (Series Editor).

22. Voter KZ, Whitin JC, Torres A, Morrow PE, Cox C, Tsai Y, Utell MJ, Frampton MW. Ozone exposure and the production of reactive oxygen species by bronchoalveolar cells in humans. Inhal Toxicol. 2001;13:465-83.

23. Kehrl HR, Vincent LM, Kowalsky RJ, Horstman DH, O'Neil JJ, McCartney WH, Bromberg PA. Ozone exposure increases respiratory epithelial permeability in humans. Am Rev Respir Dis. 1987:135:1124-8.

24. Huang W, Wang G, Phelps DS, Al-Mondhiry H, Floros J. Human SP-A genetic variants and bleomycin-induced cytokine production by THP-1 cells: effect of ozone-induced SP-A oxidation. Am J Physiol Lung Cell Mol Physiol. 2004; 286:L546-53.

25. Janic B, Umstead TM, Phelps DS, Floros J. Modulatory effects of ozone on THP-1 cells in response to SP-A stimulation. Am J Physiol Lung Cell Mol Physiol. 2005;288:L317-25.

26. Wang G, Umstead T, Phelps D, Al-Mondhiry H, Floros J. The effect of ozone exposure on the ability of human surfactant protein a variants to stimulate cytokine production. Environ Health Perspect. 2002;110:79-84.

27. Mikerov AN, Umstead TM, Gan X, Huang W, Guo X, Wang G, Phelps DS, Floros J. Impact of ozone exposure on the phagocytic activity of human surfactant protein A (SP-A) and SP-A variants. Am J Physiol Lung Cell Mol Physiol. 2008;294:L121-30.

28. Connor AJ, Laskin JD, Laskin DL. Ozone-induced lung injury and sterile inflammation. Role of toll-like receptor 4. Exp Mol Pathol. 2012;92:229-35.

29. Cho HY, Morgan DL, Bauer AK, Kleeberger SR. Signal transduction pathways of tumor necrosis factor-mediated lung injury induced by ozone in mice. Am J Respir Crit Care Med. 2007;175:829-39.

30. Sims EJ, Green MW, Mehta A. Decreased lung function in female but not male subjects with established cystic fibrosis-related diabetes. Diabetes Care. 2005;28:1581-7

31. Mudway IS, Kelly FJ. An investigation of inhaled ozone dose and the magnitude of airway inflammation in healthy adults. Am J Respir Crit Care Med. 2004;169:1089-95.

32. Wong CM, Thach TQ, Chau PY, Chan EK, Chung RY, Ou CQ, Yang L, Peiris JS, Thomas GN, Lam TH, et al. Part 4. Interaction between air pollution and respiratory viruses: time-series study of daily mortality and hospital admissions in Hong Kong. Res Rep Health Eff Inst. 2010:283-362.

33. Caracta CF. Gender differences in pulmonary disease. Mt Sinai J Med. 2003; 70:215-24.

34. Tam A, Churg A, Wright JL, Zhou S, Kirby M, Coxson HO, Lam S, Man SF, Sin DD. Sex differences in airway remodeling in a mouse model of chronic obstructive pulmonary disease. Am J Respir Crit Care Med. 2016;193:825-34.

35. Mikerov AN, Gan X, Umstead TM, Miller L, Chinchilli VM, Phelps DS, Floros J. Sex differences in the impact of ozone on survival and alveolar macrophage function of mice after Klebsiella pneumoniae infection. Respir Res. 2008;9:24.

36. Durrani F, Phelps DS, Weisz J, Silveyra P, Hu S, Mikerov AN, Floros J. Gonadal hormones and oxidative stress interaction differentially affects survival of male and female mice after lung Klebsiella pneumoniae infection. Exp Lung Res. 2012;38:165-72

37. Mikerov AN, Cooper TK, Wang G, Hu S, Umstead TM, Phelps DS, Floros J. Histopathologic evaluation of lung and extrapulmonary tissues show sex differences in Klebsiella pneumoniae-infected mice under different exposure conditions. Int J Physiol Pathophysiol Pharmacol. 2011;3:176-90.

38. Mikerov AN, Phelps DS, Gan X, Umstead TM, Haque R, Wang G, Floros J. Effect of ozone exposure and infection on bronchoalveolar lavage: sex differences in response patterns. Toxicol Lett. 2014;230:333-44.

39. Wang G, Guo X, Diangelo S, Thomas NJ, Floros J. Humanized SFTPA1 and SFTPA2 transgenic mice reveal functional divergence of SP-A1 and SP-A2: formation of tubular myelin in vivo requires both gene products. J Biol Chem. 2010;285:11998-2010.

40. Haque R, Umstead TM, Ponnuru P, Guo X, Hawgood S, Phelps DS, Floros J. Role of surfactant protein-A (SP-A) in lung injury in response to acute ozone exposure of SP-A deficient mice. Toxicol Appl Pharmacol. 2007;220:72-82.

41. Umstead TM, Phelps DS, Wang G, Floros J, Tarkington BK. In vitro exposure of proteins to ozone. Toxicol Mech Methods. 2002;12:1-16.

42. Sun J, Nishiyama T, Shimizu K, Kadota K. TCC: an R package for comparing tag count data with robust normalization strategies. BMC Bioinformatics. 2013;14:219.

43. Benjamini Y, Drai D, Elmer G, Kafkafi N, Golani I. Controlling the false discovery rate in behavior genetics research. Behav Brain Res. 2001;125:279-84.

44. Tufekci KU, Oner MG, Genc S, Genc K. MicroRNAs and multiple sclerosis. Autoimmune Dis. 2011;2011:807426.

45. Xu J, Liao X, Wong C. Downregulations of B-cell lymphoma 2 and myeloid cell leukemia sequence 1 by microRNA 153 induce apoptosis in a glioblastoma cell line DBTRG-05MG. Int J Cancer. 2010;126:1029-35.

46. Guo LM, Pu Y, Han Z, Liu T, Li YX, Liu M, Li X, Tang H. MicroRNA-9 inhibits ovarian cancer cell growth through regulation of NF-kappaB1. FEBS J. 2009; 276:5537-46.

47. Myatt SS, Wang J, Monteiro LJ, Christian M, Ho KK, Fusi L, Dina RE, Brosens JJ, Ghaem-Maghami S, Lam EW. Definition of microRNAs that repress expression of the tumor suppressor gene FOXO1 in endometrial cancer. Cancer Res. 2010;70:367-77.

48. Phelps DS, Umstead TM, Silveyra P, Hu S, Wang G, Floros J. Differences in the alveolar macrophage proteome in transgenic mice expressing human SP-A1 and SP-A2. J Proteom Genom Res. 2013:1:2-26.

49. Mikerov AN, Umstead TM, Huang W, Liu W, Phelps D, Floros J. SP-A1 and SP-A2 variants differentially enhance association of Pseudomonas aeruginosa with rat alveolar macrophages. Am J Physiol Lung Cell Mol Physiol. 2005; 288:L150-8.

50. Mikerov AN, Umstead TM, Huang W, Liu W, Phelps DS, Floros J. SP-A1 and SP-A2 variants differentially enhance association of Pseudomonas aeruginosa with rat alveolar macrophages. Am J Physiol Lung Cell Mol Physiol. 2005;288:L150-8.

51. Phelps DS, Umstead TM, Floros J. Sex differences in the acute in vivo effects of different human SP-A variants on the mouse alveolar macrophage proteome. J Proteome. 2014:108:427-44.

52. Scheller J, Chalaris A, Schmidt-Arras D, Rose-John S. The pro- and antiinflammatory properties of the cytokine interleukin-6. Biochim Biophys Acta. 1813;2011:878-88.

53. Waxman AB, Kolliputi N. IL-6 protects against hyperoxia-induced mitochondrial damage via BCl-2-induced Bak interactions with mitofusins. Am J Respir Cell Mol Biol. 2009:41:385-96.

54. Moore TC, Bush KL, Cody L, Brown DM, Petro TM. Control of early Theiler's murine encephalomyelitis virus replication in macrophages by interleukin- 6 occurs in conjunction with STAT1 activation and nitric oxide production. J Virol. 2012;86:10841-51.

55. Nguyen VA, Gao B. Cross-talk between alpha(1B)-adrenergic receptor (alpha(1B)AR) and interleukin-6 (IL-6) signaling pathways. Activation of alpha(1b)AR inhibits il-6-activated STAT3 in hepatic cells by a p42/44 mitogenactivated protein kinase-dependent mechanism. J Biol Chem. 1999;274:35492-8.

56. Miller AM, Wang H, Park O, Horiguchi N, Lafdil F, Mukhopadhyay P, Moh A, Fu XY, Kunos G, Pacher P, Gao B. Anti-inflammatory and anti-apoptotic roles of endothelial cell STAT3 in alcoholic liver injury. Alcohol Clin Exp Res. 2010:34:719-25.

57. Myung SJ, Yoon JH, Yu SJ. STAT3 \& cytochrome P450 2C9: a novel signaling pathway in liver cancer stem cells. Biomed Pharmacother. 2012;66:612-6.

58. Piekorz RP, Nemetz C, Hocke GM. Members of the family of IL-6-type cytokines activate Stat5a in various cell types. Biochem Biophys Res Commun. 1997;236:438-43. 
59. Zhang Z, Jones S, Hagood JS, Fuentes NL, Fuller GM. STAT3 acts as a coactivator of glucocorticoid receptor signaling. J Biol Chem. 1997;272:30607-10.

60. Carballo M, Conde M, El Bekay R, Martin-Nieto J, Camacho MJ, Monteseirin J, Conde J, Bedoya FJ, Sobrino F. Oxidative stress triggers STAT3 tyrosine phosphorylation and nuclear translocation in human lymphocytes. J Biol Chem. 1999;274:17580-6.

61. Li L, Zhang J, Diao W, Wang D, Wei Y, Zhang CY, Zen K. MicroRNA-155 and MicroRNA-21 promote the expansion of functional myeloid-derived suppressor cells. J Immunol. 2014;192:1034-43.

62. Hegde VL, Tomar S, Jackson A, Rao R, Yang X, Singh UP, Singh NP, Nagarkatti PS, Nagarkatti M. Distinct microRNA expression profile and targeted biological pathways in functional myeloid-derived suppressor cells induced by $\Delta$ 9-tetrahydrocannabinol in vivo: regulation of CCAAT/enhancer-binding protein a by microRNA-690. J Biol Chem. 2013;288:36810-26.

63. Iliopoulos D, Jaeger SA, Hirsch HA, Bulyk ML, Struhl K. STAT3 activation of miR-21 and miR-181b-1 via PTEN and CYLD are part of the epigenetic switch linking inflammation to cancer. Mol Cell. 2010;39:493-506.

64. $\mathrm{Ng} H$, Yeap YY, Ong LS, Jans DA, Bogoyevitch MA. Oxidative stress impairs multiple regulatory events to drive persistent cytokine-stimulated STAT3 phosphorylation. Biochim Biophys Acta. 1843;2014:483-94.

65. Levy DE, Darnell JE Jr. Stats: transcriptional control and biological impact. Nat Rev Mol Cell Biol. 2002;3:651-62.

66. Yu H, Pardoll D, Jove R. STATs in cancer inflammation and immunity: a leading role for STAT3. Nat Rev Cancer. 2009;9:798-809.

67. Barre B, Avril S, Coqueret O. Opposite regulation of myc and p21waf1 transcription by STAT3 proteins. J Biol Chem. 2003;278:2990-6.

68. Drakopanagiotakis F, Xifteri A, Tsiambas E, Karameris A, Tsakanika K, Karagiannidis N, Mermigkis D, Polychronopoulos V, Bouros D. Decreased apoptotic rate of alveolar macrophages of patients with idiopathic pulmonary fibrosis. Pulm Med. 2012;2012:981730.

69. Cimmino A, Calin GA, Fabbri M, lorio MV, Ferracin M, Shimizu M, Wojcik SE, Aqeilan Rl, Zupo S, Dono M, et al. miR-15 and miR-16 induce apoptosis by targeting BCL2. Proc Natl Acad Sci U S A. 2005;102:13944-9.

70. Xia L, Zhang D, Du R, Pan Y, Zhao L, Sun S, Hong L, Liu J, Fan D. miR-15b and miR-16 modulate multidrug resistance by targeting $B C L 2$ in human gastric cancer cells. Int J Cancer. 2008;123:372-9.

71. Hayden MS, West AP, Ghosh S. NF-kappaB and the immune response. Oncogene. 2006;25:6758-80.

72. Rath PC, Aggarwal BB. Antiproliferative effects of IFN-alpha correlate with the downregulation of nuclear factor-kappa B in human Burkitt lymphoma Daudi cells. J Interf Cytokine Res. 2001;21:523-8.

73. Luo JL, Kamata $H$, Karin M. IKK/NF-kappaB signaling: balancing life and death-a new approach to cancer therapy. J Clin Invest. 2005;115:2625-32.

74. Koptides M, Umstead TM, Floros J, Phelps DS. Surfactant protein A activates NF-kappa B in the THP-1 monocytic cell line. Am J Phys. 1997;273:L382-8.

75. He G, Karin M. NF-KB and STAT3-key players in liver inflammation and cancer. Cell Res. 2011;21:159-68.

76. Haugen F, Drevon CA. Activation of nuclear factor-kappaB by high molecular weight and globular adiponectin. Endocrinology. 2007;148:5478-86.

77. Shah A, Verma AS, Patel KH, Noel R, Rivera-Amill V, Silverstein PS, Chaudhary S, Bhat HK, Stamatatos L, Singh DP, et al. HIV-1 gp120 induces expression of IL-6 through a nuclear factor-kappa B-dependent mechanism: suppression by gp120 specific small interfering RNA. PLoS One. 2011;6:e21261.

78. Snyder M, Huang J, Huang XY, Zhang JJ. A signal transducer and activator of transcription 3.nuclear factor $\mathrm{KB}$ (Stat3.NFkB) complex is necessary for the expression of fascin in metastatic breast cancer cells in response to interleukin (IL)-6 and tumor necrosis factor (TNF)-a. J Biol Chem. 2014;289:30082-9.

79. Zhang Y, Wang F, Lan Y, Zhou D, Ren X, Zhao L, Zhang Q. Roles of microRNA-146a and microRNA-181b in regulating the secretion of tumor necrosis factor-alpha and interleukin-1beta in silicon dioxide-induced NR8383 rat macrophages. Mol Med Rep. 2015;12:5587-93.

80. Heckman CA, Mehew JW, Boxer LM. NF-kappaB activates BCl-2 expression in $\mathrm{t}(14,18)$ lymphoma cells. Oncogene. 2002;21:3898-908.

81. Jacque E, Schweighoffer E, Visekruna A, Papoutsopoulou S, Janzen J, Zillwood R, Tarlinton DM, Tybulewicz VL, Ley SC. IKK-induced NF-kB1 p105 proteolysis is critical for $B$ cell antibody responses to $T$ cell-dependent antigen. J Exp Med. 2014;211:2085-101.
82. Wang LS, Li L, Chu S, Shiang KD, Li M, Sun HY, Xu J, Xiao FJ, Sun G, Rossi JJ, et al. MicroRNA-486 regulates normal erythropoiesis and enhances growth and modulates drug response in CML progenitors. Blood. 2015;125:1302-13.

83. Essers MA, Weijzen S, de Vries-Smits AM, Saarloos I, de Ruiter ND, Bos J Burgering BM. FOXO transcription factor activation by oxidative stress mediated by the small GTPase Ral and JNK. EMBO J. 2004;23:4802-12.

\section{Submit your next manuscript to BioMed Central and we will help you at every step:}

- We accept pre-submission inquiries

- Our selector tool helps you to find the most relevant journal

- We provide round the clock customer support

- Convenient online submission

- Thorough peer review

- Inclusion in PubMed and all major indexing services

- Maximum visibility for your research

Submit your manuscript at www.biomedcentral.com/submit
Biomed Central 